Clothing Cultures

Volume 4 Number 3

(c) 2017 Intellect Ltd Article. English language. doi: 10.1386/cc.4.3.235_1
KATHERINE TOWNSEND AND JULIANA SISSONS

Nottingham Trent University

ANIA SADKOWSKA

Coventry University

\section{Emotional Fit: Developing a new fashion methodology with older women}

\section{KEYWORDS}

fashion methodology older women ageing bodies interpretative phenomenological analysis emotional knowledge 


\section{Introduction}

The term 'Emotional Fit' has been assigned to this research project to reflect the emotive and technical terrain of the investigation. The female participants and researchers share concerns about the current state of fashionable clothing for mature women and are exploring the issue through experimental, co-creative, practice. The aim of the collaborative engagement is to develop a collection of innovatively designed, well-fitting garment prototypes that meet, but ultimately highlight, the aesthetic and emotional needs of this growing demographic. To contextualize the study, there are now 11.8 million people aged 65 or over in the UK (Age UK 2017), approximately one fifth of the population, who represent vast economic potential and a wealth of experiential knowledge in terms of the phenomenon of fashion. In spite of this, in most Western societies, mature women have often failed to be considered (or consulted) as a prime or target market by designers and mainstream retailers resulting in a form of sociocultural invisibility (Church Gibson 2000). Although this situation is slowly beginning to be addressed by the design world, the legacy of neglect is reflected by the high street and ready-to-wear collections offered by the fashion and clothing industry, who have continually overlooked (if not intentionally ignored) this segment of the population. This scenario represents a missed opportunity for the fashion industry, resulting in dissatisfaction and frustration, particularly amongst older female customers who have a strong sense of their identity and 'agency' through their varied and tacit experiences of selecting, making, adapting, styling and wearing clothes. The women's embodied fashion knowledge has developed from their lasting relationship with clothing, influenced by the cultural revolution of 1960s Britain, which acted as the backdrop to their coming of age.

Returning to the reasons for the failure of designers to address the needs of an ageing demographic, Professor of Social Policy and Sociology at the University of Kent, Julia Twigg comments that'fashion and age sit uncomfortably together' (Twigg 2013: 1). Furthermore, she defines ageing as a form of 'disruption', highlighting the lack of acceptance of this phenomenon within society. In response to this situation, the authors argue that in order to address this significant, specialist market sector through innovation, an holistic research methodology is required that both responds to and augments the aesthetic, physiological and emotional considerations informing this burgeoning area of design. In this article, we report on the working progress and preliminary findings stemming from the exploratory stages of the project, which are informing the methodology.

Our first steps towards developing the methodology required the research team to more fully understand and explore the relationship between ageing females and their sense of agency through fashion. In order to achieve this, it was necessary to evaluate mature women's experiential knowledge of wearing fashion, resulting in the following initial research objectives:

- to explore how fashion and clothing are experienced and remembered by a sample of mature British women over the age of 55

- to understand their issues with sizing and fit

- to discover their aesthetic and emotional design needs

- to create a series of womenswear prototypes that reflect their emotional design needs and preferences.

The first three objectives have and continue to be addressed through a qualitative investigation utilizing methods such as creative workshops and in-depth 
interviews, but the fulfilment of the final objective will be facilitated through the development of a series of co-created potential clothing designs encapsulating aesthetics, innovative garment shaping, fitting and sizing solutions. The project builds on the authors' related research into fashion and ageing (Sadkowska et al. 2014), creative pattern cutting (including zero waste) and sculptural shaping (Townsend and Mills 2013; Sissons 2010), hybrid technical and simultaneous fashion and textile design approaches (Townsend 2004b). The research also considers the role of emotion as a catalyst within practice (Niedderer and Townsend 2014) longevity and emotional durability (Chapman 2015) through collaborative 'diffuse and expert design' for social innovation (Manzini 2015: 37). Significantly, this research triangulates these design approaches with psychological insights into how mature women wear clothes, by considering how fashion products and feelings that once defined the past can potentially become the key to'un-locking'the present (Sadkowska et al. 2014) and facilitate a dialogue between the wearer(s) and designer(s). This involves a conceptual and exploratory fashion practice, whereby an interdisciplinary methodology is developed and applied through the balancing of theory and practice, which we explain below.

\section{Research context and rationale}

Growing old and the experience of it has become a significant topic in the contemporary social research agenda, due to increased human lifespans, which together with the presence of the post-World War II baby boomers, has impacted upon the growth and associated clothing needs of an ageing population (McCann and Bryson 2014). The post-industrial economy of improved healthcare, leisure opportunities and bio-medical technologies have affected both the biological and social spheres of growing old, improving opportunities but also producing new challenges for ageing identities across the gender spectrum (Powell and Gilbert 2009; Fraser and Greco 2005; Featherstone and Hepworth 1991). As Gilleard and Higgs (2005) note, the current ageing generation is the one that created a consumer culture built on youth and sexuality, 'so that their attainment of the Third Age status marks a new stage in the cultural constitution of age' (Twigg 2007: 300). In this 'contemporary age of aging' (Powell and Gilbert 2009: vii), the postmodern approach disrupts the constrained perceptions of growing old, placing emphasis on the individuals, their bodies and identities, experiences, actions, practices and dynamics.

'[P]ersons remake themselves over time, and thus their identities change' (Arxer et al. 2009: 46); human biographies have the potential to be translated as the relationships between personal and structural factors. Consequently, individual and collective experiences, where fashion and clothes, as the communicators and mediators between self and society (Entwistle 2002; Entwistle and Wilson 2001; Crane 2000), can become the key to analyse and particularly understand ageing identities. In the same vein, Twigg argues that '[clothes] offer a useful lens through which to explore the possibly changing ways in which older identities are constituted in modern culture' (Twigg 2009a: 93). The phenomenological approach, therefore, with its emphasis on practice and experience, enables 'un-locking an understanding of what it means to be a human person situated within and across the life course' (Powell and Gilbert 2009: 5). When it comes to fashion and clothing, phenomenology provides the possibility to 'uncover the multiple and culturally constructed meanings that a whole range of events and experiences can have for us' (Weber and Mitchell 2004: 4) and to establish the interrelation between the stories of individuals, objects and times they inhabit. 
Through Emotional Fit, we exploit these interrelations, with regards to mature women over the age of 55 who share common interests and enthusiasm for fashion and clothing. Their dedication has developed through various fashion-related practices including purchasing, adapting, dressmaking from patterns, creating from scratch, styling, customizing, recycling and more, in support of how they have and continue to present themselves in their everyday lives. Moreover, as fashion and textile designers, practitioners and researchers, we aim to utilize our theoretical and tacit knowledge and skills to create a series of garment prototypes that cater for the stylistic (fashion) and practical/functional (clothing) needs and expectations of mature women as identified by the sample.

For the purposes of this project, we distinguish between the terms of 'fashion' and 'clothing'. Furthermore, we subscribe to Teunissen's rather conceptual definition of 'fashion' as being 'the product of a design that [is] "attached" to the human body but that also [seeks] to research and explore its own relationship with the body, with identity, self-image, and the environment' (2013: 201). Consequently, following Joanne B. Eicher, we adopt the definition of clothing'as a noun refer[ing] generally to articles that cover the body' (2010: 151). At the same time, however, we also recognize, following Kawamura, the existence of a commonly accepted simplification in which fashion often functions as 'clothing fashion, that is, the most trendy, up-to-date clothing that the majority of the people in society adopts and follows' (2011: 9). This consideration is especially relevant when it comes to analysing and interpreting our informants' accounts of their experiences of fashion and clothing.

\section{Methodology and data}

Previous investigations into both ageing and fashion have often adopted a qualitative approach through in-depth interviews (Holland 2004, 2012; Grimstad Klepp and Storm-Mathisen 2005; Davis 2012) and have focussed on specific aspects including older women's clothing choices (Hurd Clarke et al. 2009; Holmlund et al. 2011). While these studies have revealed issues of relevance to the current research, they reveal little of the meaning of fashion through the individual experience of ageing and identity in the lives of mature women. Few studies have attempted to establish the relationship between memory and clothing (Twigg 2009b, 2010), but there are some limited, good examples of textile and fashion research projects that explicitly touch on the role of emotion. These include Wallace's Dress Box (2009) from her'Personhood in Dementia' project, which utilized remnants of fabrics from dresses made in the 1960s and 1970s to naturally trigger memories from this time (Niedderer and Townsend 2014: 16) and Stead's (2005) Ph.D. study,'The Emotional Wardrobe', focussed on the integration of technology with clothing to stimulate and represent emotion. Some researchers have adapted a phenomenological approach by extending the traditional form of interview with the analysis of artefacts, such as textiles, garments and photographs (Lerpiniere 2009; Weber and Mitchell 2004), and workshops for participants (Richards et al. 2012). However, to date, only a small number of researchers have combined such methods, which makes this methodology particularly innovative with its equal emphasis on theoretical and practical research methods that seek to expand existing knowledge through an intergenerational dialogue and associated outcomes. 
Accordingly, this project consists of three phases (Figure 1) and includes multiple case studies of members of the Nottingham, UK female population between the ages of 55-75. The three phases cover, in order: research, design and findings dissemination. Each phase is designed to build iteratively on the findings from the previous stage and by employing different but complementary research methods throughout, as presented below. In this article, our

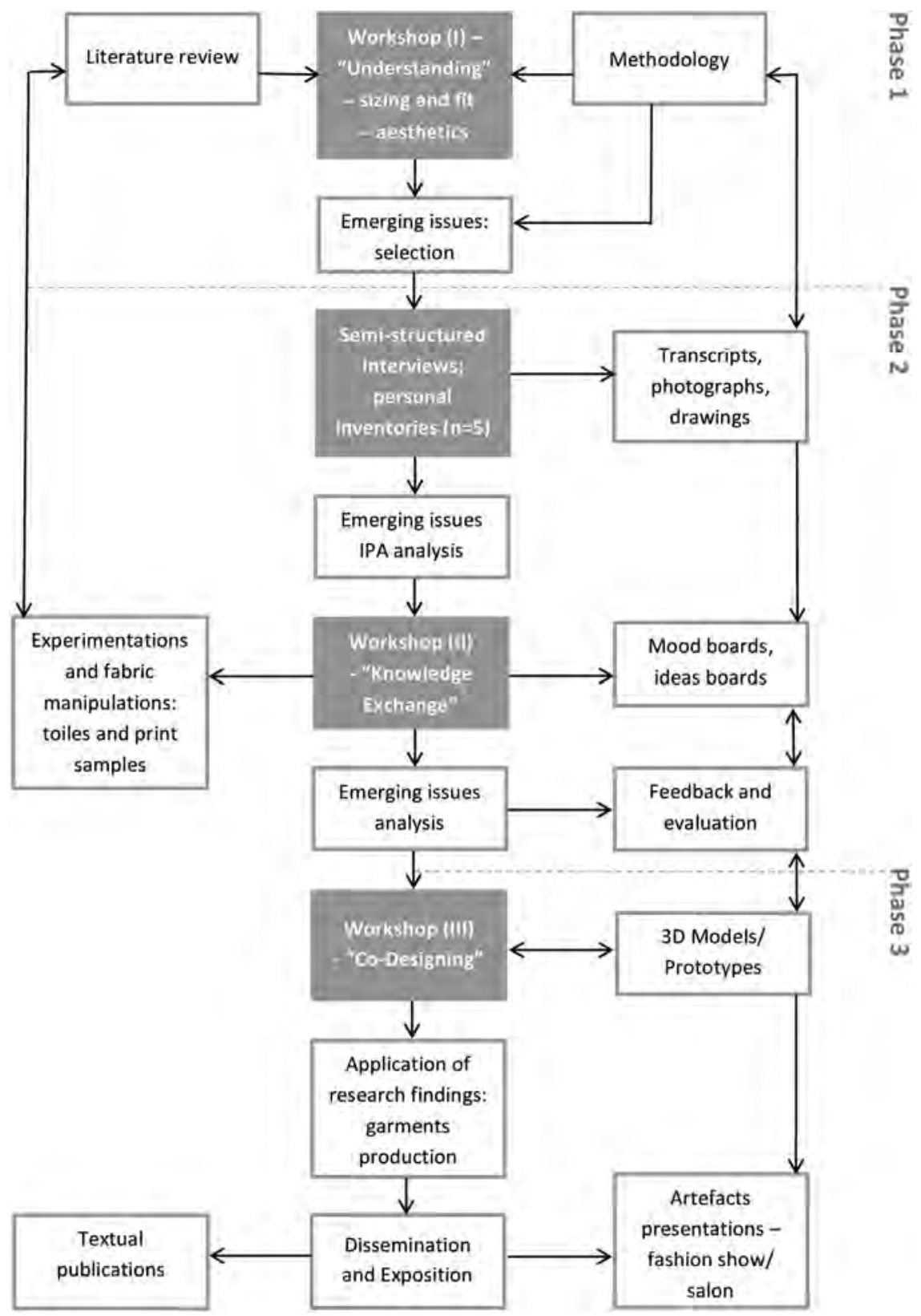

Figure 1: Emotional Fit project - research model. (C) Emotional Fit 2015. 
primary focus is on the first two phases of the project, especially the methods employed in workshops and interviews to illicit qualitative data. However, we also touch on the envisaged co-designing approach in Phase 3.

\section{Workshop (I): ‘Understanding’ - May 2015 Nottingham Trent University}

In the first stage of the project, our aim was clear: we wanted to develop a primary understanding of what problems and issues older women have and share regarding fashion and clothing. In order to fulfil this aim, we organized a workshop with ten participants (Table 1), with the three researchers and a research assistant as the facilitators. The workshop lasted three hours.

In order to stimulate the process of understanding the complexity of the participants' experiences, we first invited them to introduce themselves and freely discuss their personal issues regarding their clothes (Figure 2). Interestingly, without prompting from the facilitators, most of the participants discussed their issues to be located within two areas: firstly, 'fit', including problems relating to the inconsistent sizing systems on the British high street; secondly, 'aesthetics'. Here, the issue that caused the most frustration was that recurrent fashion trends were nearly all explicitly aimed at young bodies. Our participants felt disappointed with the high street, with the exception of key brands (including Cos, Toast and Kin), by not taking into account the physical changes, naturally occurring to female bodies as they age. The women in our study felt that it was socially'expected' of them to cover the neuralgic parts of their bodies such as arms and elbows, neck, cleavage and thighs.

The participants also made references to the 'skin' and its changing texture, density and decolourization through ageing. They also felt that the colours widely available in the shops often did not compliment their appearances; black and white were their classic/regular choices; however, this selection was often dictated by the unsuitability of other colours rather than the their specific preferences. As indicated by the workshop participants, problems seemed to lie not in the colours per se but in their tonal range. In contrast,

\begin{tabular}{lll}
\hline Name $^{*}$ & Age & Occupation \\
\hline Anna $^{1,2}$ & 64 & Retired \\
Barbara $^{1,2}$ & 65 & Semi-retired/part-time university researcher \\
Christine $^{1,2}$ & 65 & Retired \\
Debbie $^{1}$ & 62 & Retired \\
Elizabeth $^{1,2}$ & 67 & Retired \\
Fran $^{1}$ & 66 & Retired \\
Georgina $^{1}$ & 55 & Retired \\
Hannah $^{1,2}$ & 65 & Retired \\
Irene $^{1}$ & 66 & Retired \\
Josephine & 75 & Retired \\
\hline
\end{tabular}

* Pseudonyms were used to protect the participants' anonymity.

${ }^{1}$ Participants who expressed their interest in being interviewed.

${ }^{2}$ Participants interviewed.

Table 1: Sample characteristics. 


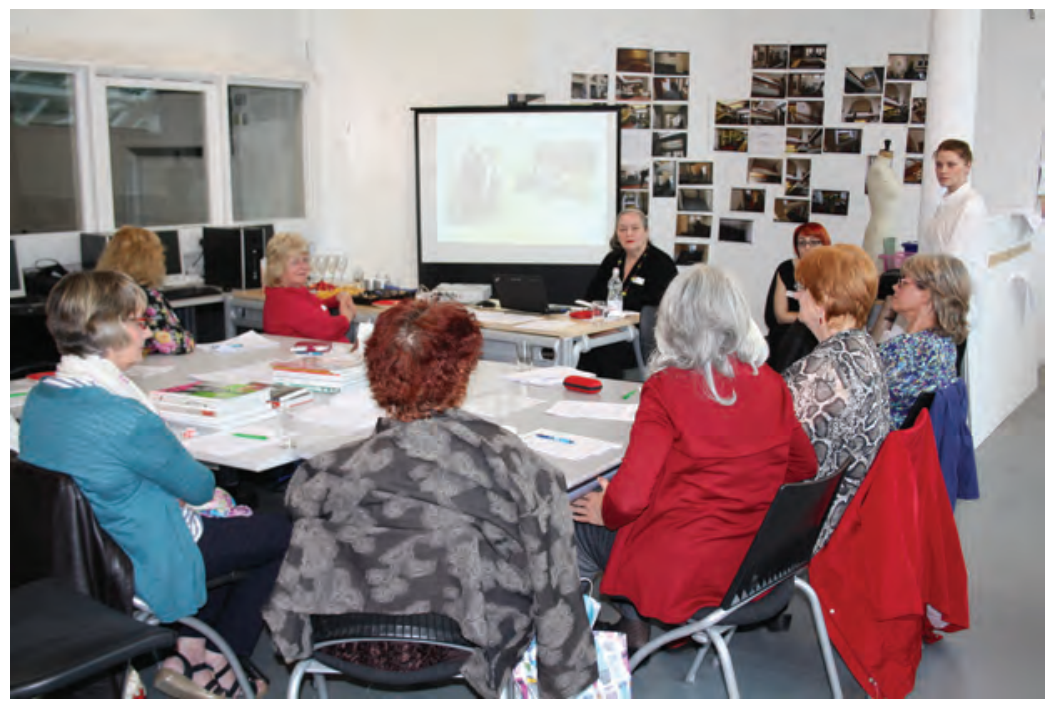

Figure 2: Participants introducing themselves and their clothing preferences and issues. (C) Emotional Fit 2015.

all of the women present expressed rather negative attitudes towards colours such as grey or beige through related descriptors of 'granny-ish' and 'boring'. These colour shades or 'neutrals' are considered as part of the staple colour palettes for the mature fashion market. Discussion around this issue raised interesting psychological perceptions between ageing and semantics, particularly the notion that once past a certain age women become 'invisible' or 'neutralised' within Western culture, perpetuated by a feeling that commercial fashion is not designed 'for them'.

Secondly, we invited our participants to tell us about their favourite and least favourite items of clothing, which they were requested to bring to the workshop. Although this was designed as an individual exercise and we spoke to each woman individually about the items of clothing they brought in (recording their accounts), it quickly developed into a group discussion where the participants had a chance to discuss their preferences amongst themselves as well as compare and contrast their clothing within the sample group (Figures $3 a$ and $b$ ).

Alongside this activity, the participants had a chance to look at current fashion magazines such as Another Magazine, Vogue and Elle and relate their needs and tastes to the various images, editorials and adverts presented in these publications. This provided a platform for them to make a direct comparison between the fashionable clothes on offer with items of clothing that are actually present in their wardrobes. Once again, for many, this was a chance to express their dissatisfaction with the fashion solutions currently available on the market. On the other hand, these women presented a high level of creativity and widely commented that in fact they would buy some of these products but modify them according to their own needs, for example by adding sleeves or elongating the shape of a garment. Overall, the women commented that they did not feel there was anything that was entirely suitable for their bodies as presented to them in the magazines, and in fact, they reported that they rarely buy fashion magazines themselves. Once again, this 

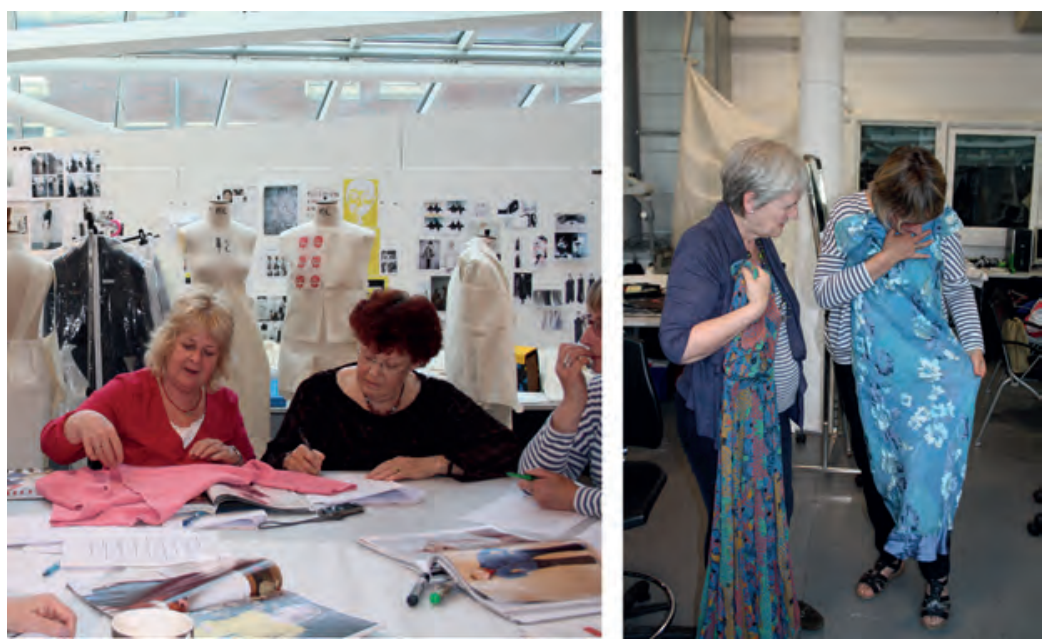

Figures 3: (a-b) Participants showing and discussing their favourite items and selecting images from magazines to highlight stylistic preferences. (C) Emotional Fit 2015.
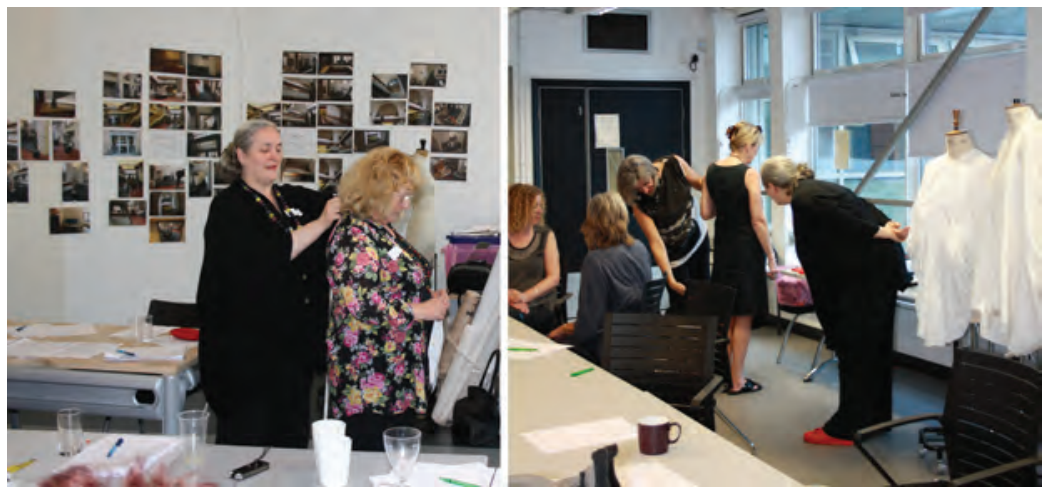

Figure 4: (a-b) Taking detailed measurements of two of the participants to inform the production of bespoke pattern blocks. OEmotional Fit 2015.

highlights the women's disconnection with fashion and clothing as produced and sold by the British fashion industry to the so-called grey(ing) market. The final element of the workshop was to take detailed measurements of each participant (Figure 4).

The measurements accrued from Workshop (I) were utilized in the Phase 2 of the project (Figure 1), as data for the production of a series of bespoke pattern blocks devised by Juliana Sissons. The blocks informed a series of experimental garment patterns and silhouettes based on the principles of creative pattern cutting to achieve zero or minimal waste (Sissons 2010; Rissanen and McQuillan 2015; Townsend and Mills 2013).

\section{Workshop (I): Findings}

As stated in the Introduction, the research question we aim to answer in this project is: 'how can womenswear be designed more effectively to meet the 
physical and emotional requirements of an ageing female demographic?' In order to fulfil this aim a core objective is to explore the co-creative potential of communicating messages between the project participants (wearers) and the designers. Similarly, Press and Cooper (2003) identify three areas of design research: 'understanding of the phenomenon, generating ideas and proposing solutions'. The role of Workshop (I) was precisely to allow us to understand the ageing phenomenon as experienced and interpreted by the participants. Furthermore, Lawson (2006: 125) describes the design process as 'endless' and claims that designing, unlike completing mathematical operations, cannot have a predetermined end and, therefore, it should be described as overlapping loops repeated within time intervals allowing for analysis and reflection. Chapman (2015), Niedderer and Townsend (2014) and Niinimaki and Koskiken (2011) also argue that in order to design longevity into products, we need to incorporate lasting emotional and sustainable/material as well as physical perspectives. Adapting these concepts is a crucial aspect of the proposed research model, with the constant evaluation of findings informing the evolving methodology and design practice, through the testing and sampling of the developing solutions.

In this vein, Workshop (I) had an exploratory as well as generative purpose and was designed to 'allow the designer[s] to see and understand the relevance of objects in a user's life from the participant's point of view, to inspire design themes and insights' (Martin and Hanington 2012: 130). The gathered visual information, i.e. photos and images (such as tear sheets from magazines), was captured and stored in the form of mood boards, to serve as a direct introduction to the practical work (toiles and prototypes), which seeks to address some of the participants' evolving design needs.

\section{Interviews}

The first element of the second phase of study was to conduct five in-depth interviews with selected participants. The interviewees were randomly selected from the participants at Workshop (I), who declared their interest in being interviewed (Table 1). The interviews were designed to be semi-structured, face-to-face informal conversations, 'so that the rapport between researcher and informant will be enhanced, and that the corresponding understanding and confidence between the two will lead to in depth and accurate information' (Kumar 2005: 124). Moreover, these interviews, conducted by Ania Sadkowska, were devised to enable each participant to explicate in detail about their individual experiences of fashion and ageing.

Each interview was conversational in style and lasted between 60 and 80 minutes and was digitally recorded and transcribed verbatim with consent from each participant. The interview schedule consisted of sixteen openended questions about different aspects of women's experiences of fashion and clothing, to find out about the meaning of fashion in the participants' lives, their shopping practices and future expectations of fashion. The participants were also asked to describe critical occasions when they felt really good/bad (positive/negative) about the way they looked. Themes emerging from the transcribed interviews were meticulously analysed using interpretative phenomenological analysis (IPA), to build on the cultural context via the personal histories and experiences of the participants, which will be used as inspiration to create fashion prototypes. To date, analysis of the material gathered through the interviews has revealed various tensions in older women's 
perceptions of the current fashion and clothing system as well as contradictions regarding their expectations towards it.

\section{Sense of belonging}

To begin, the majority of the participants asserted that they felt privileged because of the generation they were part of. This was present in the narratives of all five participants who on numerous occasions highlighted the personal connections with certain fashion practices and behaviours originated in 1960s. Furthermore, they felt extremely positive about certain British fashion designers who started their design brands in the 1960s and 1970s and are still present in the fashion market such as Vivienne Westwood and Paul Smith. From international designers, the two most commonly mentioned were Yohji Yamamoto and Issey Miayke. Overall, the tone of these cultural connections was that some designers, perhaps due to their own ageing, could relate and therefore design garments more empathetically for older women. In contrast, other labels such as Biba were often discussed with considerable nostalgia. In the following extract, Elizabeth (67) explains the importance of wearing some of these labels through her personal reflections:

So it was the sixties [...] that is when it [fashion] started to really affect, yeah change people really. Yes, I can remember buying my first Biba outfit and my friend got married in Biba. So we were [...] and of course they had mail order then. Also there was only one Laura Ashley shop, and again at the time Laura Ashley was kind of fantastic. We went to London especially to go to the one Laura Ashley shop. Then when it kind of comes to opening in all of the towns it's not the same. It's like Next, once it started to open everywhere it wasn't as interesting. It then became stuff for the masses and it wasn't individual somehow. You had to look very hard to find individual things.

What is compelling in this extract is a certain sense of a shared generational uniqueness as well personal sense of individuality experienced by Elizabeth from being a teenager in a period when developments in fashion were particularly dramatic. In this vein, further on in her interview, she reflects: 'I feel I have been very lucky that there has been Mary Quant andVivienne Westwood and Paul Smith. [...] And I still think that man [Paul Smith] is a hero'.

Similar reflections were present in all interviews. Of particular importance is the shift in cultural and social perceptions relating to how women should present themselves. This was strongly connected to the contemporary fashion solutions of the time, as Christine (65) explained:

I suppose [...] Somebody like Mary Quant was quite important for my sort of generation. Because she introduced, I mean it came with the development of tights, I think (laughs). You could wear, as I did, we could wear very short skirts and tights. And not feel as we were revealing everything. And she has, I think, introduced more the shift style.

These extracts convey that the interviewees shared a strong generational sense of belonging. Furthermore, they shared positive attitudes towards certain fashion designers who they witnessed developing their brands as well as to other designers who are no longer present in the market or have changed direction. 


\section{Fashion awareness}

As well as discussing their past interest in fashion, all the interviewees expressed a strong current interest in fashion trends. However, this was often discussed in relation to their own bodily conditions such as height or weight. In the following extract, Elizabeth (67) explains how she finds out about changing trends:

I love to kind of look at fashion in magazines and even when it was the fashion show at the time. And I suppose you look and I was interested in what was translated too, from the catwalk into the everyday. And it's interesting, and I like to read in the papers and magazines how people have taken things. And how they have translated it into more everyday things, and it can be colours, it can be shapes, and it could be hemlines. I find all of that very interesting. But I suppose I, being small and round I have never been a fashionable shape.

A similar picture is presented by Christine (65) who explains that her own body type has become a lens through which she filters suitable fashion trends:

So I have always looked at magazines, uhm, I have always been interested in what's been in the shops, but, uhm. In my early days I didn't have a lot of money and I have always been in a way conscious of my body type. So I think that is as much as anything, it's my body type that has determined my interest in fashion.

This type of a 'targeted' fashion awareness, where women exhibit a lifelong interest in fashion, allows them to not only understand their aesthetic preferences but also the impact of their physical condition on how clothing is presented on and through their body. Furthermore, this is critically important when it comes to developing any potential designs that target these groups of women because this evidenced a clear understanding of their 'dressed body' type (Entwistle 2002: 133).

\section{Bodily changes}

Another important theme that emerged, through analysis of the interviews, was the bodily changes occurring to and affecting women's self-esteem (Church Gibson 2000) and sense of identity (Crane 2000) as they grow older. Interestingly, one of the most common comments in the interviews was of the specific social limitations linked to exposure of the mature female body. In the following extract, Elizabeth (67), who elsewhere in her interview highlighted the importance of being influenced by Mary Quant and wearing mini skirts when she was younger, comments on the unsuitability of such solutions for older women, regardless of their physiques, who can be perceived as 'mutton dressed as lamb' by 'trying look young and it doesn't work'.

Similar opinions were shared by most of the participants. In the following extract, however, Christine (65) presents a slightly different point of view:

I am dressing for my generation of women. Who are [...] not wanting to look young. But who just don't want to abandon clothes, which are perhaps more youthful, yeah. So I mean, I probably do dress for my age now, because for example, uhm, I would like my arms covered up. 
I don't tend to wear [...] although I could wear lower necks [...] I don't like to show a lot of flesh, let's put it like that. So I wouldn't reveal a lot of flesh. Whether that's dressing for my age, or just dressing for me.

Interestingly, here Christine again highlights the importance of a certain generational identity amongst women similar to her age and social norms relating to how they should dress their bodies (Entwistle and Wilson 2001). However, despite recognizing certain social limitations as to what older women should and should not wear, Christine attempts to detach herself from being restricted in this way, by explaining her clothing choices in regards to her current lifestyle - that is, she'could wear lower necks', but chooses not to.

\section{Personal trajectories}

The final theme, which emerged from this series of interviews, was the influence of personal trajectories on our participants' current interest and engagement with fashion. The personal histories our participants shared with us differed significantly from each other. For example, one woman had experienced serious health issues affecting what kind of clothing she preferred to wear to conceal changes to her body. Another participant discussed the significant impact that the death of her husband had on the way she chooses her clothes. In her interview, she explained that she not only lost a great and dedicated clothing advisor in her husband, but also that now, as a widow she does not want to present herself as a woman'searching for a new husband':

It's almost as if they [some of her female friends] think I'll jump on their husbands or something and there is a bit of [...] I kind of feel I need to be a little bit more conservative about what I wear. I am not looking for anybody else and I don't want people to even think that I am, I was very happy. So it's a silly thing.

Consequently, we argue that these personal trajectories are important when it comes to design for mature women, especially when the aim is to achieve a state of equilibrium: a sense of emotional fit between the design and the wearer.

\section{Interviews: Findings and implications}

Following Workshop (I), the semi-structured in-depth interviews had an exploratory as well as generative purpose, designed to allow the researchers to understand the psychological aspects of how mature women experience fashion and clothing more deeply. The interviews revealed various tensions, as well as contradictions in relation to the participants' fashion behaviours and practices. Firstly, they all expressed a strong, common sense of generational belonging, which clearly influenced their expectations, in terms of perceived connections with designers and the designing process, which they clearly valued. Based on this finding, we plan to make our presence and motivations as designers as accessible as possible, working with the participants as our co-designers and potential wearers. This approach supports an emotionally durable design ethos, where products are often 'user tested' prior to production (Chapman 2015). It is also in line with bespoke or couture practice but challenges 'fast fashion' and mass production.

Secondly, the participants exhibited strong awareness of current fashion trends, however, always in relation to their own physiques. Again, this 
highlights the need to develop new fashion design methodologies and solutions that consider wearers unique bodily features more empathetically alongside contemporary cultural conditions. Many women expressed an interest in clothing that can potentially enhance the way they present their mature bodies rather than masking them or creating the false impression of being a younger age. Finally, it is worth re-iterating that all the interviewed women have had very different life courses resulting in unique value systems and expectations in regards to fashion and clothing. In order to be successful, the design process needs to acknowledge these personal trajectories within the constraints of the proposed research model (Figure 1).

Based on these findings, the garment prototypes will be constructed in different'size groupings' to accommodate all the individuals within the sample. Textile samples will be sourced based on the data accrued through the workshops and interviews, relating to the women's current lifestyles, perceived clothing needs for the future (McCann and Bryson 2014) and considerations relating to emotionally durable design and longevity (Chapman 2015). Katherine Townsend will lead on the development of a series of bespoke digital prints, designed in response to the aesthetic preferences but also the personal narratives divulged through formal and spontaneous conversations about textiles and clothing between the participants and researchers. Printed garment prototypes will be designed using Sisson's geometric patterns and by adopting a 'simultaneous approach' (Townsend 2004a) whereby the print imagery is scaled and manipulated in relation to the evolving 3D garment silhouettes, by modelling them on the (moving and still) women's bodies. This way of working responds to the notion of the individual's form being articulated through clothing and that this can be achieved more effectively through the bespoke integration of print and cut, image and cloth to 'contour' and empathize with the woman's aesthetic preferences and physical and characteristics. By adopting an emotionally durable approach, we aim to produce garment designs (and design principles) that enable the women to express their maturity and agency (Niinimaki and Koskiken 2011).

\section{Conclusion}

In this article, we have presented and discussed the preliminary findings from the first two phases of the research project entitled 'Emotional Fit: Mapping the aging female form'. The research question, which we aim to answer through this project, is: 'how can womenswear be designed more effectively to meet the physical and emotional requirements of an ageing female demographic?' In this vein, our aim is to explore mature women's relationship with fashion and clothing. The first two phases of this qualitative project involved two iterations of Workshop (I): 'Understanding' with participants $(n=10+11)$ and a series of in-depth interviews $(n=5)$. Since writing this article, Workshop (II): 'Knowledge exchange' has been conducted (July 2015) with similar and new participants $(n=12+9)$ to accrue further individual measurements, to test the fit of initial specialist sized blocks and toiles and to generate additional feedback and inform the developing fashion methodology through the ongoing co-designing process. Workshop (III): 'Co-designing' also took place in April 2016 but does not affect the focus of this article to disseminate the methodological approach.

The initial results of the project have allowed us to develop an in-depth understanding of how the participants in the study experience, practice and 
engage with fashionable clothing on a daily basis. Furthermore, the utilization of an exploratory workshop and in-depth interviews as research methods enabled us to discover the complex nature of the participants' experience. The two key aspects identified were related to the women's aesthetic expectations, often developed throughout their lifelong interest in and engagement with fashion and clothing, as well as problems with sizing and fit. Our next step (Phase 3) of the project will be to continue to utilize the gathered information and measurements and respond to it via creative fashion practice including techniques of geometric pattern cutting, bespoke textile designs that respond to both garment and body shape, computerized and traditional fashion and textile crafting techniques. A collaborative, diffused design approach will support the ongoing research and subsequent outcomes through further workshops and a public dissemination event presented to other researchers and key industry stakeholders. The originality of the research methodology and its potential innovative outcomes lies in its merging of IPA, the analysis of the women's lived experience of fashion, with a simultaneous fashion and textile design approach, that holistically considers not only the size but the physical and emotional shape of mature women.

\section{ACKNOWLEDGEMENTS}

The authors would like to thank all the women from Nottingham who have participated in the study.

\section{REFERENCES}

Age UK (2017), 'Later life in the United Kingdom', August, https://www. ageuk.org.uk/Documents/EN-GB/Factsheets/Later_Life_UK_factsheet. pdf?dtrk=true. Accessed 15 September 2017.

Arxer, S., Murphy, J. and Belgrave, L. (2009),'Social imagery: Aging and, and the life course: A postmodern assessment', in J. Powell and T. Gilbert (eds), Aging Identity: A Dialogue with Postmodernism, New York: Nova Science, pp. 45-55.

Chapman, J. (2015), Emotionally Durable Design: Objects, Experiences, Empathy, London: Routledge.

Church Gibson, P. (2000), 'No-one expects me anywhere', in S. Bruzzi and P. Church Gibson (eds), Fashion Cultures: Theories, Explorations and Analysis, London: Routledge, pp. 79-89.

Crane, D. (2000), Fashion and Its Social Agendas: Class, Gender, and Identity in Clothing, London: The University of Chicago Press.

Davis, J. (2012), 'Punk, ageing and the expectations of adult life', in A. Bennett and P. Hodkinson (eds), Ageing and Youth Cultures. Music, Style and Identity, London: Berg, pp. 105-18.

Eicher, J. B. (2010), 'Clothing, costume, and dress', in V. Steele (ed.), The Berg Companion to Fashion, Oxford: Berg, pp. 151-52.

Entwistle, J. (2002), 'The dressed body', in M. Evans and E. Lee (eds), Real Bodies: A Sociological Introduction, Basingstoke: Palgrave, pp. 133-50.

Entwistle, J. and Wilson, E. (2001), Body Dressing: Dress, Body, Culture, Oxford, UK: Berg.

Featherstone, M. and Hepworth, M. (1991), 'The mask of ageing and the postmodern life course', in M. Featherstone, M. Hepworth and B. Turner (eds), The Body: Social Process and Cultural Theory, London: Sage, pp. 371-89.

Fraser, M. and Greco, M. (2005), 'Introduction', in M. Fraser and M. Greco (eds), The Body: A Reader, London: Rutledge, pp. 1-42. 
Gibson, L. (2012), 'Rock fans' experiences of the ageing body: Becoming more "civilized"', in A. Bennett and P. Hodkinson (eds), Ageing and Youth Cultures: Music, Style and Identity, London: Berg, pp. 79-91.

Gilleard, C. and Higgs, P. (2005), Contexts of Ageing: Class, Cohort and Community, Malden, MA: Polity Press.

Grimstad Klepp, I. and Storm-Mathisen, A. (2005), 'Reading fashion as age: Teenage girl's and grown Women's accounts of clothing as body and social status', Fashion Theory, 9:3, pp. 323-42.

Holland, S. (2004), Alternative Femininities: Body, Age and Identity, Oxford, UK: Berg.

- (2012), 'Alternative women adjusting to ageing, or how to stay freaky at 50', in A. Bennett and P. Hodkinson (eds), Ageing and Youth Cultures: Music, Style and Identity, London: Berg, pp. 119-30.

Holmlund, M., Hagman, A. and Polsa, P. (2011), 'An exploration of how mature women buy clothing: Empirical insights and a model', Journal of Fashion Marketing and Management, 15:1, pp. 108-22.

Hurd Clarke, L., Griffin, M. and Meliha, K. (2009), 'Bat wings, bunions, and turkey wattles: Body transgressions and older women's strategic clothing choices', Ageing and Society, 29:5, pp. 709-26.

Kawamura, Y. (2011), Doing Research in Fashion and Dress, Oxford, UK: Berg.

Kumar, R. (2005), Research Methodology, London: Sage.

Lawson, B. (2006), How Designers Think: The Design Process Demystified, 4th ed., Oxford, UK: Architectural, pp. 123-26.

Lerpiniere, C. (2009), 'The fabric snapshot - phenomenology, fashion and family memory', in E. Rouse (ed.), Fashion \& Wellbeing - IFFTI Conference Proceedings, London College of Fashion, London, pp. 279-90.

Manzini, E. (2015), Design, When Everybody Designs - An Introduction to Design for Social Innovation, Cambridge, MA: The MIT Press.

Martin, B. and Hanington, B. (2012), Universal Methods of Design, Beverly: Rockport Publishers.

McCann, J. and Bryson, D. (eds) (2014), Textile-led Design for the Active Ageing Population, Cambridge, UK: Woodhead.

Niedderer, K. and Townsend, K. (2014), 'Designing craft research: Joining emotion and knowledge', Design Journal, 17:4, pp. 634-48.

Niinimaki, K. and Koskiken, I. (2011), 'I love this dress, it makes me feel beautiful: Emotional knowledge in sustainable design', The Design Journal, 14:2, pp. 165-86.

Powell, J. and Gilbert, T. (2009), 'Phenomenologies of aging - critical reflections', in J. Powell and T. Gilbert (eds), Aging Identity: A Dialogue with Postmodernism, New York: Nova Science, pp. 5-16.

Press, M. and Cooper, P. (2003), The Design Experience: The Role of Design and Designers in the Twenty-first Century, Aldershot, UK: Ashgate.

Richards, N., Warren, L. and Gott, M. (2012), 'The challenge of creating "alternative" images of ageing: Lessons from a project with older women', Journal of Aging Studies, 26, pp. 65-78.

Rissanen, T. and McQuillan, H. (2015), Zero Waste Fashion, London and Oxford, UK: Bloomsbury.

Sadkowska, A. M. (2012), 'The dys-appearing body project: Design for sociocultural context of well-being and sustainability', Unpublished MA thesis, Leicester, UK: De Montfort University.

Sadkowska, A., Fisher, T., Wilde, D. and Townsend, K. (2014), 'Interpreting fashion and age: Arts-informed interpretative phenomenological analysis 
as a fashion research methodology', The Fashion Thinking, History, Theory, Practice, University of Southern Denmark, Kolding, Denmark, 30 October1 November.

Sissons, J. (2010), Basics Fashion Design 06: Knitwear, London: AVA Publishing.

Stead, L. J. (2005), 'The emotional wardrobe: A fashion perspective on the integration of technology and clothing', Unpublished Ph.D. thesis, London: University of the Arts.

Teunissen, J. (2013), 'Fashion: More than cloth and form', in S. Black, A. De La Haye, J. Entwistle, A. Rocamora, R. Root and H. Thomas (eds), The Handbook of Fashion Studies, London: Bloomsbury, pp. 197-213.

Townsend, K. (2004a), 'Transforming shape: A simultaneous approach to the body, cloth and print for textile and garment design (synthesising CAD with manual methods)', unpublished Ph.D. thesis, Nottingham, UK: Nottingham Trent University.

- (2004b), 'Transforming shape: Hybrid practice as group activity', Design Journal: Pixel Raiders Issue, 7:2, pp. 18-31.

Townsend, K. and Mills, F. (2013), 'Mastering zero: How the pursuit of less waste leads to more creative pattern cutting', International Journal of Fashion Design, Technology \& Education, 6:2, pp. 104-11.

Twigg, J. (2007), 'Clothing, age and the body: A critical review', Ageing and Society, 27, pp. 285-305.

- (2009a), 'Clothing, identity and the embodiment of age', in J. Powell and T. Gilbert (eds), Aging Identity: A Dialogue with Postmodernism, New York: Nova Science, pp. 93-104.

- (2009b), 'Dress and the narration of life: Women's reflections on clothing and age', in A. C. Sparkes (ed.), Auto/Biography Yearbook 2009: BSA Auto/Biography Study Group, Nottingham: Russell Press, pp. 1-18.

- (2010), 'Clothing and dementia: A neglected dimension?', Journal of Aging Studies, 24, pp. 223-30.

(2013), Fashion and Age: Dress, the Body and Later Life, London: Bloomsbury.

Weber, S. and Mitchell, C. (eds) (2004), Not Just Any Dress: Narratives of Memory, Body, and Identity, Oxford, UK: Peter Lang.

\section{SUGGESTED CITATION}

Townsend, K., Sissons, J. and Sadkowska, A. (2017),'Emotional Fit: Developing a new fashion methodology with older women', Clothing Cultures, 4:3, pp. 235-251, doi: 10.1386/cc.4.3.235_1

\section{CONTRIBUTOR DETAILS}

Dr Katherine Townsend is an associate professor in fashion and textile crafts in the School of Art and Design at Nottingham Trent University. Her current research projects, 'Emotional Fit: Developing a new fashion methodology with mature women' and 'The electric corset and other future histories', explore material and cultural issues in fashion, textiles and ageing and the use of costume archives to inform the design of e-textiles and wearables. Her research into the role of embodied knowledge in the digital crafting of textiles was recently published in the chapter 'Closely held secrets', in Crafting Textiles in the Digital Age (Bloomsbury 2016). She is co-editor of the journal, Craft Research. 
Contact: School of Art and Design, Nottingham Trent University, 50 Shakespeare Street, Nottingham NG1 4GG, United Kingdom.

E-mail: katherine.townsend@ntu.ac.uk

Juliana Sissons is a creative pattern cutter, knitwear designer and senior lecturer at Nottingham Trent University. Her research focuses on the development of sculptural techniques in textile manipulation and pattern cutting. As a designer in residence at the V\&A Museum, she has had the opportunity to work with a number of curators to display her collections in the galleries as part of the London Design Festival.

Contact: School of Art and Design, Nottingham Trent University, 50 Shakespeare Street, Nottingham NG1 4GG, United Kingdom.

E-mail: juliana.sissons@ntu.ac.uk

Dr Ania Sadkowska is a fashion designer, lecturer and researcher at Coventry University, UK. In the past, she worked as a lecturer and research fellow at Nottingham Trent University, UK. Her research explores the intersection of sociology and psychology with art and design practices. Current projects span a variety of topics, including fashion and ageing, masculinity, phenomenology and art and design research methodologies. Ania has presented work at various UK and international conferences and exhibitions, including in Italy, China, Sweden and the US. Recently, her research paper has been published in Age, Culture, Humanities: An Interdisciplinary Journal (special issue on Fashion and Ageing). Since 2014, she has been involved in a co-creative research project titled 'Emotional Fit: Developing a new fashion methodology with older women'.

Contact: School of Art and Design, Faculty of Arts and Humanities, Coventry University, Priory Street, Coventry CV1 5FB, United Kingdom.

E-mail: ac3739@coventry.ac.uk

Katherine Townsend, Juliana Sissons and Ania Sadkowska have asserted their right under the Copyright, Designs and Patents Act, 1988, to be identified as the authors of this work in the format that was submitted to Intellect Ltd. 